Reprod. Nutr. Dévelop., 1986, 26 (2 A), 475-486.

\title{
Digestion par la trypsine de la coque de l'œuf de carpe (Cyprinus carpio L.) et incubation des embryons sans coque
}

\author{
J. PASCARD ( $\left.{ }^{1}\right)\left({ }^{2}\right)$, Catherine CHAILLOU $\left({ }^{1}\right)\left({ }^{2}\right)\left({ }^{*}\right)$, P. ROUBAUD (1) ( $\left.{ }^{2}\right)$, \\ Pierrette REINAUD (1)
}

Avec les collaborations techniques: Installations piscicoles expérimentales: G. FAYMENDI, P. LEBRENN, E. LETELLIER et D. MARIE. Entretien des laboratoires : Marie-Louise PETINON et RoseMarie PLACID. Dessin : Rose-France MASSON

(') Station de Physiologie animale, Groupe "Embryologie des Poissons, I.N.R.A., Jouy-en-Josas, 78350 France.

(2) Equipe de Biologie du Développement, Université Paris VII, 2 Place Jussieu, 75251 Paris Cedex 05.

Summary. Trypsin digestion of carp (Cyprinus carpio L.) eggshell and incubation of shell-free embryos.

The present work reports an experiment to eliminate the shell of carp eggs before the 2-cell stage and to incubate the shell-free embryos. Once this technique has been acquired, we intend to carry out studies in experimental embryology and to transfer foreign genes into fish embryos by direct DNA precipitation on the treated egg masses. In this experiment, the eggs were treated with $1 \%$ trypsin for $1 \mathrm{~min} 30 \mathrm{~s}$ at $12^{\circ} \mathrm{C}$ and then washed in an isotonic saline bath for $2 \mathrm{~h}$; shell digestion increased during the first 10 min after fertilization, after which it decreased and ceased at the end of egg activation.

Post-ovulatory ageing made the oocytes resistent to the treatment.

Embryo integrity depended on egg turgescence at shell rupture; embryos extruded through the first opening in the shell were more traumatized in water than in saline solution.

These results have been interpreted with reference to the water inflow related with formation of the perivitelline space and shell hardening during egg activation.

The eggs could be incubated up to the hatched fry stage in the isotonic solution but yield was low.

Multiple embryos were formed by clustering prior to epiboly. The factors affecting the incubation yield of shell-free eggs are discussed.

\section{Introduction.}

L'élimination précoce de la coque de l'œuf de poisson est une étape nécessaire aux recherches sur le rôle de la coque et de l'espace périvitellin, ou sur les effets des toxiques au cours du développement embryonnaire.

Récemment, nous avons formulé le projet d'utiliser le nombre très élevé des œufs fournis par des espèces comme la carpe, pour leur appliquer certaines des

$\left({ }^{*}\right\rangle$ à qui toute correspondance doit être adressée : Equipe de Biologie du Développement, Anatomie comparée, Université Paris VII, 2 place Jussieu, 75251 Paris Cedex 05. 
techniques de transfert de gènes qui ont été mises au point sur des cellules en culture : il s'agit, par exemple, de précipiter les ADN directement sur la surface des embryons pour les faire pénétrer ensuite par un choc osmotique. Le faible rendement de cette technique exige que l'on puisse préparer et incuber en masse des embryons débarrassés de leur coque avant leur première division de segmentation.

La coque des œufs de Téléostéens est constituée d'une couche interne épaisse et résistante et d'une couche externe mince et souple (Laale, 1980). II est possible d'éliminer la couche interne par action d'un acide (Huver, 1963), ou par digestion enzymatique prolongée pendant plusieurs heures (Kanoh et Yamamoto, 1957 ; Smithberg, 1966 ; Lesseps et Cast, 1976). La couche externe paraît résister à tous ces traitements et l'élimination complète de la coque doit être terminée par dissection ou agitation. Cependant au laboratoire de A. Neyfakh à Moscou (communication personnellel, les œufs de la loche Misgurnus fossilis sont débarrassés de leur coque en quelques minutes : les œufs sont traités à partir de 3 min après la fécondation, par une solution de trypsine à $1 \%$ dans un tampon de $\mathrm{pH} 8$. Pour obtenir des embryons intacts la digestion doit être incomplète et le décoquage achevé à la pince.

II est possible de disséquer la coque de l'ovocyte sous le microscope (lwamatsu, 1983), ou de forcer le passage des œufs dans un tube muni d'une lame tranchante (d'après $V$. Korzh, communication personnelle).

De toutes ces techniques, celle de Neyfakh nous a paru la plus adaptée à nos objectifs ; en effet, notre projet pour le transfert de gènes suppose que les œufs soient traités en masse et débarrassés de leur coque avant amphimixie. De plus, I'utilisation de la trypsine présente l'avantage d'avoir été reconnue compatible avec la transformation des cellules en culture.

Dans ce qui suit nous présentons nos résultats sur la digestion par la trypsine de la coque de l'œuf de carpe et sur l'incubation des embryons sans coque.

\section{Matériel et méthodes.}

Nous avons procédé à une série de 12 expériences dont 4, choisies comme étant les plus significatives, seront décrites ici.

Matériel biologique. - Chacune de ces expériences met en œuvre des ovocytes produits par des femelles différentes.

Les géniteurs, des carpes de variété miroir (Cyprinus carpio L.) âgées de 8 à 10 ans, ont été élevés en eau recyclée, de propriétés physicochimiques contrôlées (température et photopériode saisonnières de la région parisienne; $\mathrm{O}_{2}>70 \%$ de la saturation ; dureté $<300 \mathrm{mg} / \mathrm{l}$ en équivalent $\mathrm{CO}_{3} \mathrm{Ca} ; \mathrm{NH}_{3}<3,2 \mu \mathrm{g} / \mathrm{l} ; \mathrm{NO}_{2}{ }^{-}$ $<0,13 \mathrm{mg} / \mathrm{l} ; \mathrm{NO}_{3}{ }^{-}<42 \mathrm{mg} / \mathrm{l}$ ).

La production des gamètes et la fécondation ont été réalisées suivant Gillet et Roubaud (1983). La durée (dv) du vieillissement ovocytaire (c'est-à-dire, l'intervalle de temps écoulé entre l'ovulation et la fécondation) est : $d v<45 \mathrm{~min}$ : expériences 1,3 et 4 (1 1 er et $2^{\mathrm{e}}$ essais); $d v>>150 \mathrm{~min}$ : expérience 2 ; $d v \simeq$ $6 \mathrm{~h}$; expérience 4 . 
Dans l'expérience 2, en raison du vieillissement ovocytaire, le taux moyen de survie dans les lots témoins n'est que de $17,7 \%$.

Fécondation. - Les fécondations sont réalisées, dans l'expérience 2, en boîte de Pétri de $35 \times 10 \mathrm{~mm}$ de diamètre et dans les expériences 1,3 et 4 , sur un disque en voile de nylon collé (colle transfert double face Durafilm, Société Durabloc, Orgival), sur une rondelle de chlorure de polyvinyle expansé (Société Plastique Noble, Paris). La densité de cet ensemble maintient les œufs à la surface du milieu d'incubation, ce qui permet, en dehors de toute agitation, d'assurer l'oxygénation nécessaire au développement des embryons.

Deux à 3 minutes après la fécondation, le sperme est lavé à l'eau distillée, puis les œufs sont mis à incuber dans l'eau jusqu'au moment du traitement par la trypsine.

Digestion de la coque par la trypsine. - Au tout début du développement, à différents âges embryonnaires (l'âge du développement est mesuré à partir de la fécondation : $a=0$ ), les œufs sont traités par de la trypsine (Prolabo) en solution dans un tampon Tris-hydroxyméthyl-aminométhane Tris- $0,05 \mathrm{M} / \mathrm{kg}-\mathrm{HCl}$ ajusté à $\mathrm{pH} 8,0$. Les concentrations en trypsine sont : 0,$05 ; 0,4 ; 0,2 ; 0,1 \mathrm{~g} \%$ dans l'expérience 1 et $1 \mathrm{~g} \%$ dans les expériences 2,3 et 4 .

Les durées de traitement sont 1,30 min dans l'expérience $1 ; 1,30$ et 2 min dans l'expérience $2 ; 1$ et 1,30 $\mathrm{min}$ dans l'expérience 3 , et 1,30, 2 et 2,45 $\mathrm{min}$ dans l'expérience 4.

Le lavage : après traitement, la trypsine est lavée par une solution appelée « solution $\mathrm{H}$ ", d'osmolarité $300 \mathrm{mM}$ (appareil Vogel 6300 ), tamponnée à $\mathrm{pH} \mathrm{8,0}$ par $50 \mathrm{mM}$ de Tris- $\mathrm{HCl}$ et contenant : $\mathrm{KCl}: 0,2 \mathrm{~g} / \mathrm{l} ; \mathrm{NaCl}: 7 \mathrm{~g} / \mathrm{l} ; \mathrm{CaCl}_{2}, 2 \mathrm{H}_{2} \mathrm{O}$ : $0,4 \mathrm{~g} / \mathrm{l}$. Le milieu est protégé contre les bactéries et les champignons par $100 \mathrm{UI} / \mathrm{I}$ de pénicilline, $100 \mathrm{UI} / \mathrm{I}$ de streptomycine et $200 \mathrm{UI} / \mathrm{l}$ de nystatine.

Les séjours dans le bain de lavage durent 50 min dans l'expérience 1, $60 \mathrm{~min}$ dans l'expérience 2 et $120 \mathrm{~min}$ dans les expériences 3 et 4 .

De la fécondation à la fin du lavage les températures sont maintenues à $12{ }^{\circ} \mathrm{C}$ dans les expériences 1,2 et 3 , ou $13,5^{\circ} \mathrm{C}$ dans l'expérience 4 .

La digestion de la coque (décoquage) est appréciée, à l'issue du lavage, au stéréomicroscope Zoom Olympus SZ TR, sauf dans l'expérience 2 où I'on a compté les embryons qui se libèrent de leur coque en retournant leur support dans la solution de lavage.

Incubation. - Après lavage, les embryons sont portés, sans être exondés, dans des mini-incubateurs à $20^{\circ} \mathrm{C}$, contenant $200 \mathrm{ml}$ de milieu d'incubation ; dans l'expérience 4 par exemple, ce milieu est l'eau distillée sauf pour les embryons traités aux âges 16,20 et $30 \mathrm{~min}$, qui sont incubés dans la solution H. Dans certaines expériences où les œufs ne sont pas placés sur rondelles flottantes, le milieu est oxygéné par un aérateur à bulles.

Analyse statistique. - Les intervalles de confiance pour un pourcentage ont été relevés, au risque $5 \%$ (Schwartz, 1963), et les différences significatives appréciées au risque $5 \%$ par le test de $\xi^{2}$. 


\section{Résultats.}

Digestion enzymatique de la coque (fig.' 1 à 4). - Le rendement de la digestion enzymatique augmente au cours des premières minutes de l'activation (fig. 1 ).

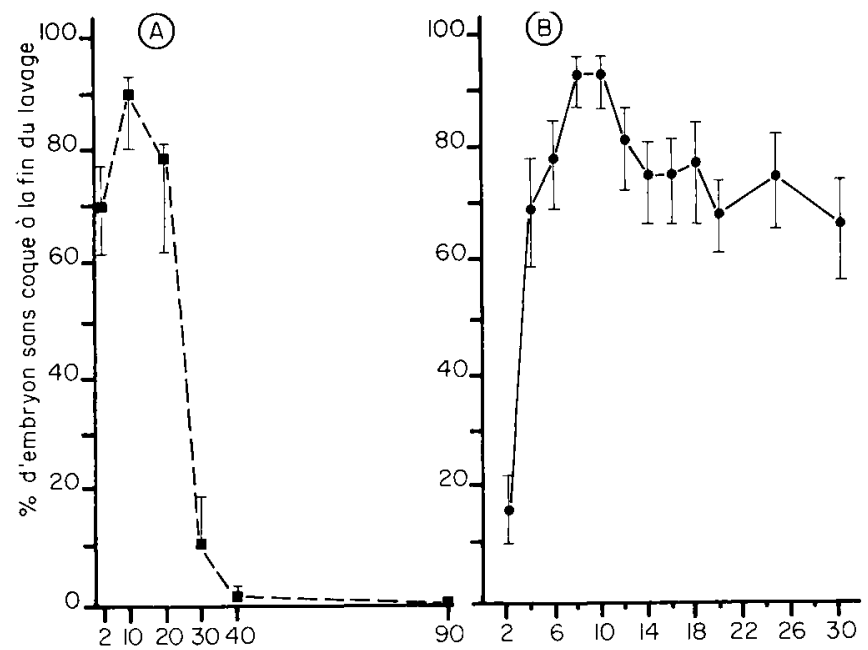

Age de l'embryon ou moment du traitement par lo trypsine (min)

FIG. $1\left(^{*}\right)$. - Variation du rendement de la digestion de la coque au cours de l'activation de l'ouf. Durée du traitement par la trypsine à $1 \mathrm{~g} / 100 \mathrm{ml}: 1,30 \mathrm{~min} ; \mathbf{0}--\mathbf{0}: \exp 3$ (fig $2 \mathrm{~A})$; - : exp. 4 (fig. 2B).

(*) Les traits de rappel verticaux représentent les intervalles de confiance statistique pour des proportions ; risque $5 \%$ (Schwartz, 1963).

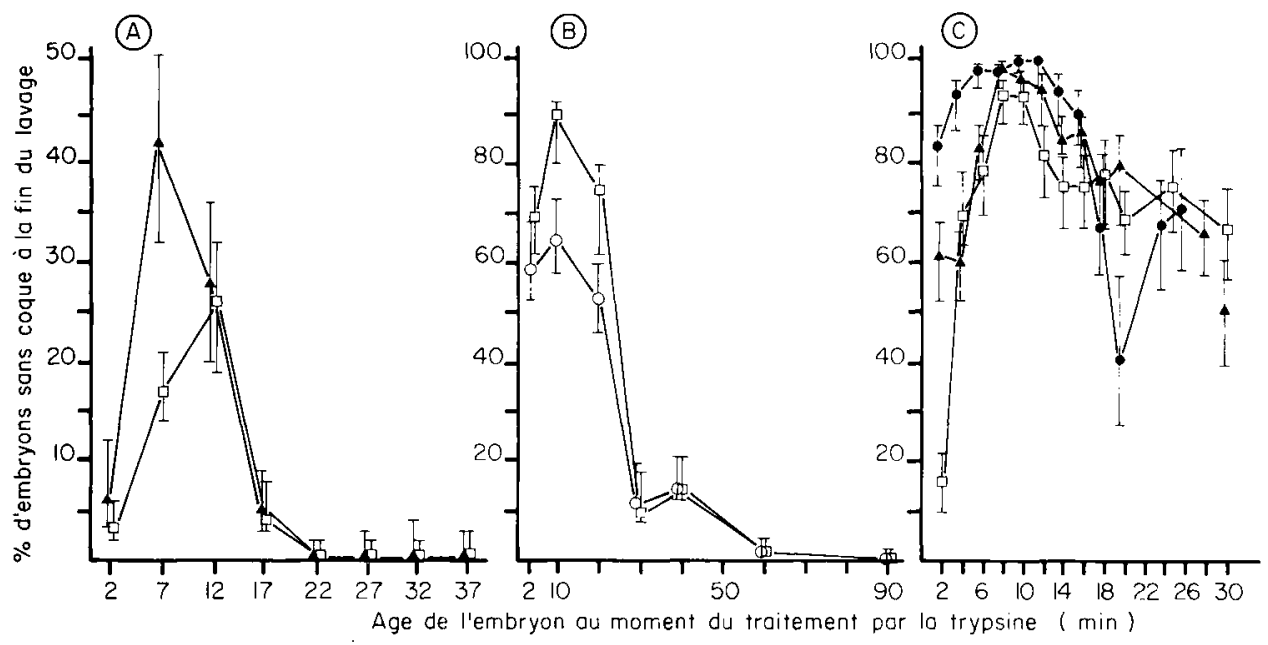

FIG. $2\left(^{*}\right)$. - Influence de la durée du traitement par la trypsine sur le rendement de la digestion de la coque. Exp. 2 (fig. 2A); exp. 3 (fig. 2B); exp. 4 (fig. 2C); concentration en trypsine : $1 \mathrm{~g} / 100$ $\mathrm{ml}$; durée du traitement : $\bigcirc-\bigcirc: 1 \mathrm{~min} ; \square \stackrel{-}{-} \square: 1,30 \mathrm{~min} ; \boldsymbol{\Delta}-\boldsymbol{\Delta}: 2 \mathrm{~min}$; - $2,45 \mathrm{~min}$.

$\left(^{*}\right)$ voir figure 1 . 
A $12{ }^{\circ} \mathrm{C}$ ou $13,5^{\circ} \mathrm{C}$, il passe par un minimum entre 7 et $12 \mathrm{~min}$ d'âge ; il décroît ensuite, pour s'annuler à la fin de l'activation.

Entre des durées de traitement de 1 et 2,45 min, le rendement augmente de façon significative (fig. 2A, B et C). Cette influence de la durée du traitement ne se manifeste qu'au début de la période d'activation.

Lorsque la concentration enzymatique est inférieure à $1 \%$, le rendement reste faible, même avec des durées de traitement supérieures à 1 min (fig. 3) : nos tentatives, comme celle de l'expérience 1, pour réduire la quantité de trypsine utilisée se sont donc soldées par des échecs.

Après lavage de la trypsine, la digestion enzymatique se poursuit au cours de I'incubation: ainsi, dans l'expérience 1, les rendements mesurés au 1er jour d'incubation sont supérieurs à ceux mesurés au moment du lavage (fig. 3B).
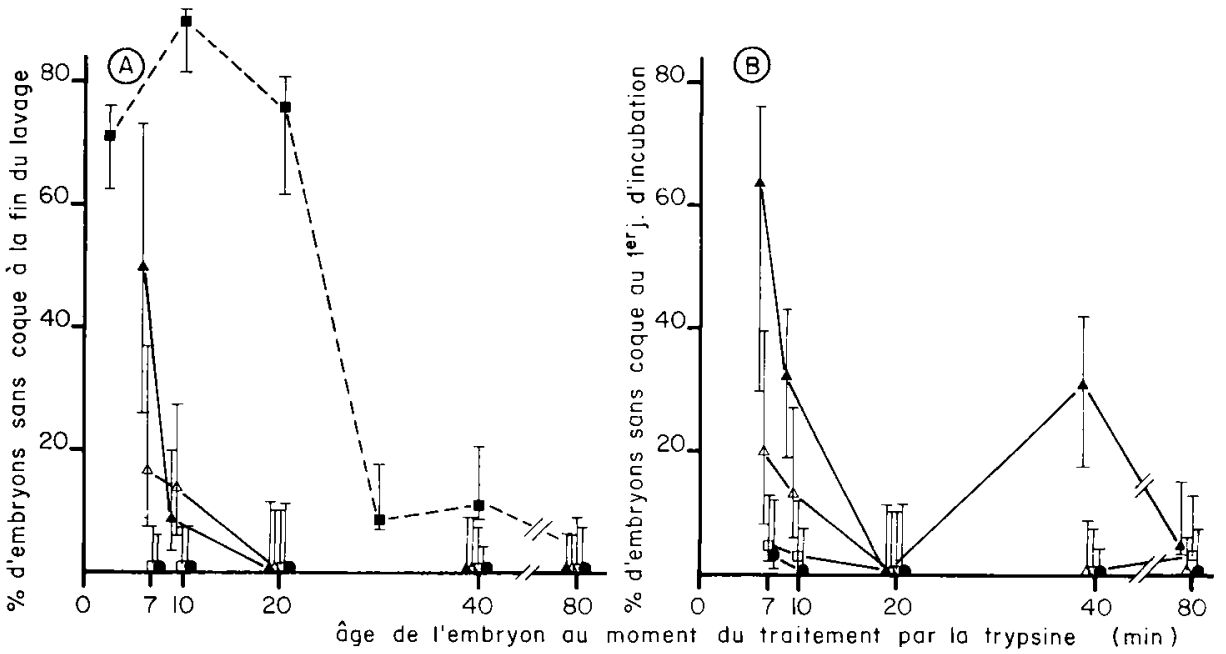

FIG. $3\left({ }^{*}\right)$. - Influence de la concentration en trypsine sur le rendement de la digestion de la coque (fig. 1A). Prolongation de la digestion de la coque au cours de l'incubation (fig. 1B) durée du traitement : 1,30 min; concentration en trypsine en $\mathrm{g} / 100 \mathrm{ml}: \exp .1: 0,05$;

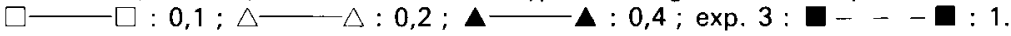

$\left(^{*}\right)$ voir figure 1

De même, nous avons toujours trouvé sur des mesures effectuées plus de $20 \mathrm{~h}$ après la fécondation, un rendement de $100 \%$ lorsque la trypsine à $1 \%$ est appliquée pendant 1,30 ou 2 min avant l'âge de $15 \mathrm{~min}$. Or, dans ces conditions, il reste toujours des embryons munis de leur coque au moment de la sortie du bain de lavage, moins de $3 \mathrm{~h}$ après la fécondation.

Le vieillissement des ovocytes in vitro dans le liquide ovarien avant fécondation correspond à une augmentation de la résistance de la coque à la digestion par la trypsine (fig. 4).

Description du processus de digestion enzymatique. - Tout d'abord, la coque devient translucide et les deux couches qui la forment deviennent discernables. Au fur et à mesure que la digestion avance, la coque s'amincit et se décolle du support. Puis, elle semble être digérée de l'intérieur, ce qui augmente l'espace 


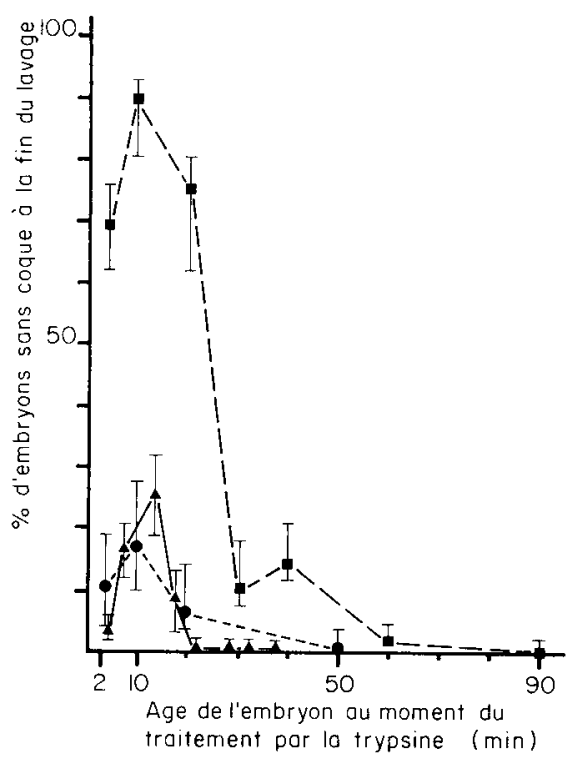

FIG. $4\left({ }^{*}\right) .-$ Effet du vieillissement des ovocytes avant fécondation sur le rendement de la digestion de la coque. Concentration en trypsine : $1 \mathrm{~g} / 100 \mathrm{ml}$; durée du traitement : 1,30 min ; durée du vieillissement ovocytaire : exp. 2: $\boldsymbol{\Delta} \Delta: d v>>150 \mathrm{~min}$; exp. 3 : $d v \simeq 360 \mathrm{~min}$ (*) voir figure 1 .

périvitellin. La couche externe résiste plus longtemps que la couche interne et forme un voile fin qui se déchire pour libérer l'embryon. C'est la sortie de la coque qui cause la plus grande part des mortalités (fig. 7) : l'embryon est alors expulsé à travers le premier orifice formé dans la coque. Si le diamètre de celui-ci est insuffisant, l'embryon est déformé et souvent déchiré lors de cette " extrusion » qui se produit de façon plus brutale dans l'eau que dans la solution $\mathrm{H}$.

Incubation des embryons sans coque. - Dans plusieurs de nos expériences, nous avons réussi à élever jusqu'à un stade postérieur à celui qui correspond normalement à l'éclosion, des embryons décoqués avant la fin de l'activation (fig. 6 et 10). Cependant, relativement au nombre des ovocytes utilisés, les taux de survie ne dépassent pas alors $20 \%$. Un certain nombre d'embryons doubles ou multiples ont été obtenus (fig. 9), les œufs s'étant accolés avant l'épibolie.

Avant l'âge de $24 \mathrm{~h}$, les embryons sans coque sont très fragiles : ils ne supportent, ni d'être exondés, ni d'être agités, par exemple, par un niveau excessif de fonctionnement de l'aérateur à bulles. La résistance aux attaques bactériennes ou fungiques est réduite, même en présence de pénicilline-streptomycine et nystatine.

Les pourcentages de survivants sont toujours moins élevés dans l'eau que dans la solution $H$, et décroissent fortement entre le $2^{e}$ et le $3^{e}$ jour d'incubation (fig 5).

Pour apprécier le rendement de la production d'embryons viables débarrassés de leur coque à la fin du lavage, c'est-à-dire, avant le stade 2 cellules (nous les noterons : $\mathrm{EC}^{-}$), il faut tenir compte, dans les taux de survie mesurés au cours de l'incubation, de ceux des embryons encore munis de leur coque à la fin du lavage $\left(E C^{+}\right)$. On suppose alors, que les $\mathrm{EC}^{+}$(en nombre $\mathrm{NEC}^{+}$), ont tous survécu par la suite. En retranchant $\mathrm{NEC}^{+}$du nombre total $\mathrm{NJ}_{1}$ des embryons encore vivants au 
1er jour d'incubation, on obtient une borne inférieure du nombre des embryons $E C^{-}$viables. Si $T$ est le nombre total des embryons traités, l'expression : $100 \frac{\mathrm{NJ}_{1}-\mathrm{NEC}^{+}}{\mathrm{T}}$ reprèsente une borne inférieure du rendement en pourcentage du $T$ procédé expérimenté.
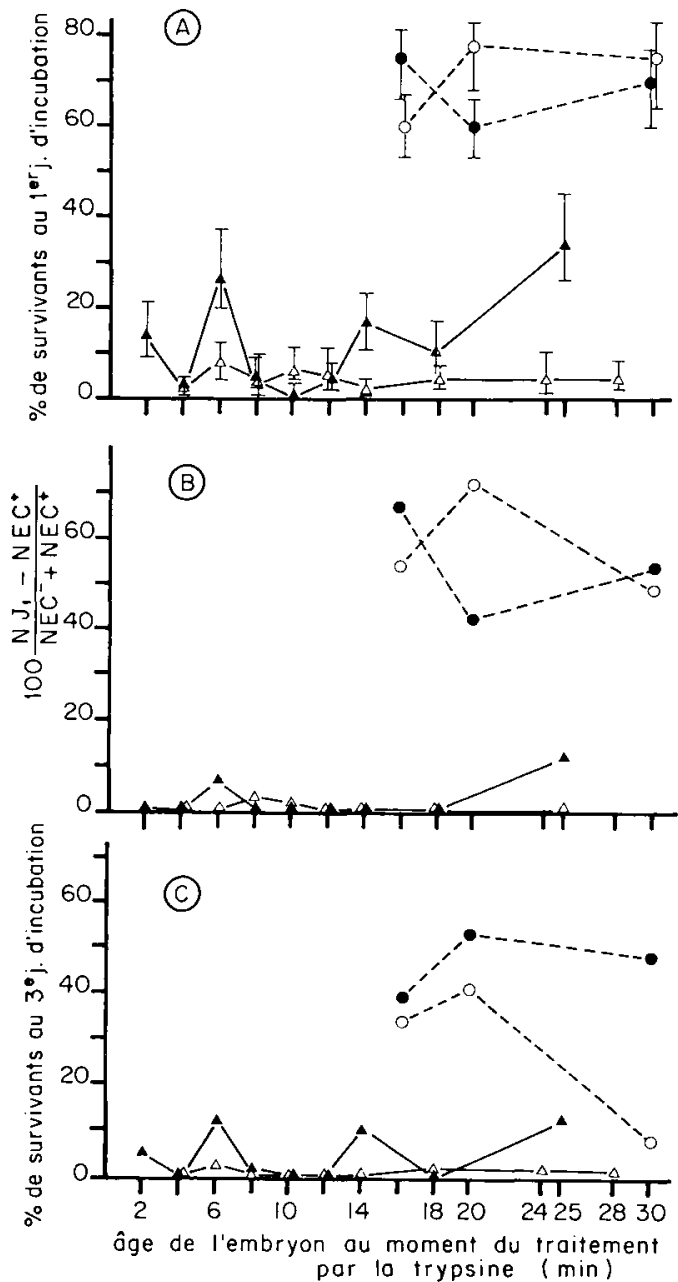

FIG. $5(*)$. - Rendements comparés de l'incubation dans l'eau et dans la solution $H$, après digestion de la coque par la trypsine : exp. 4 ; concentration en trypsine : $1 \mathrm{~g} / 100 \mathrm{ml}$; durée du traitement par la trypsine $(\min , \mathrm{sec}): \bullet-\ldots$ et $\mathbf{-} \Delta: 1,30 ; 0 \_--0$ et $\triangle \longrightarrow \triangle$ : 2,0 ; milieux d'incubation : $\mathrm{O}_{-}-\mathrm{O}$ et $-\ldots$ : solution isotonique, $\mathrm{H}$ (cf. Matériel et méthode) : $\triangle \longrightarrow \triangle$ et $\boldsymbol{\Delta} \mathbf{\Delta}$ : eau distillée. $\left(^{*}\right)$ voir figure 1.

Dans plusieurs expériences, les œufs décoqués à l'âge de 20 min ou plus, ont mieux résisté à l'incubation que ceux qui ont été décoqués à l'âge de $10 \mathrm{~min}$. Cependant, nous avons observé qu'après un traitement prolongé par la trypsine 

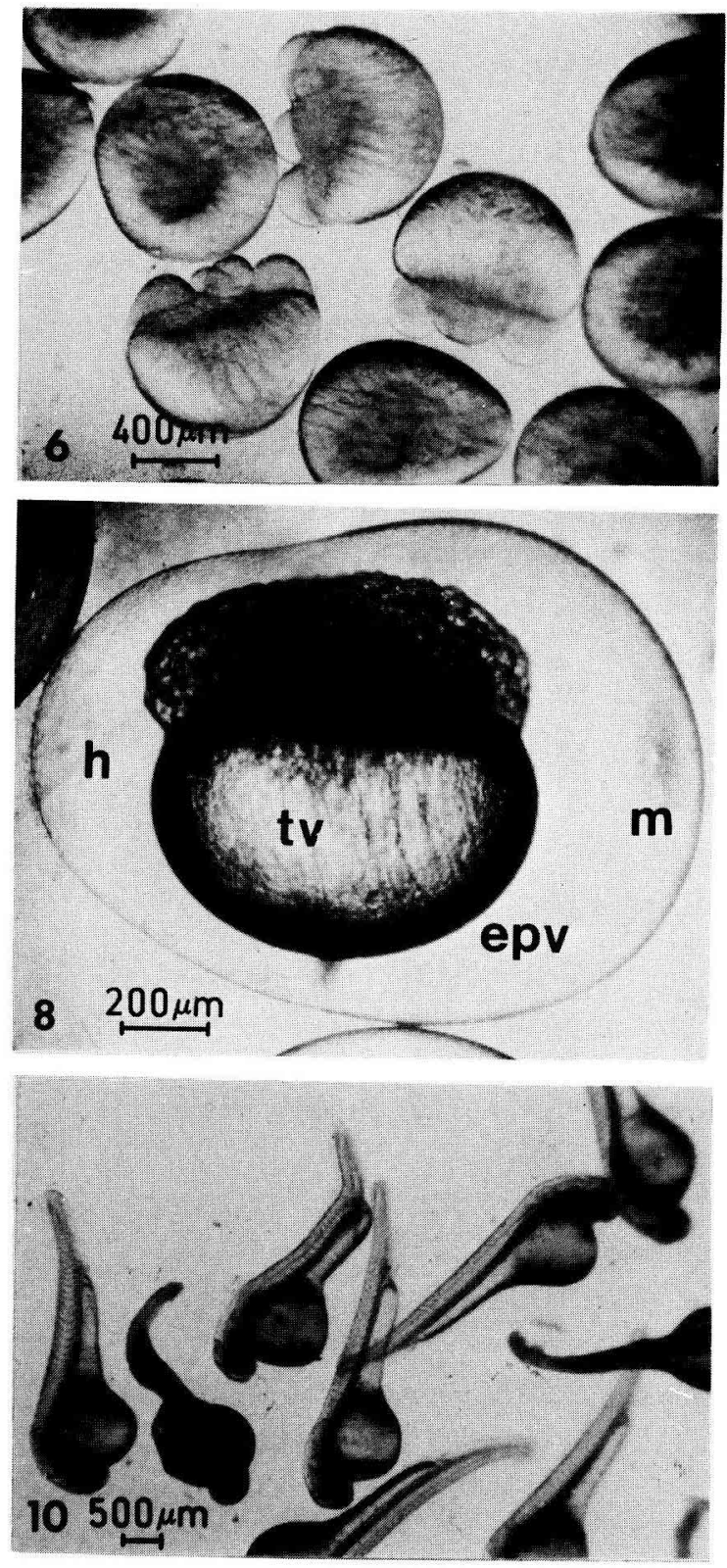
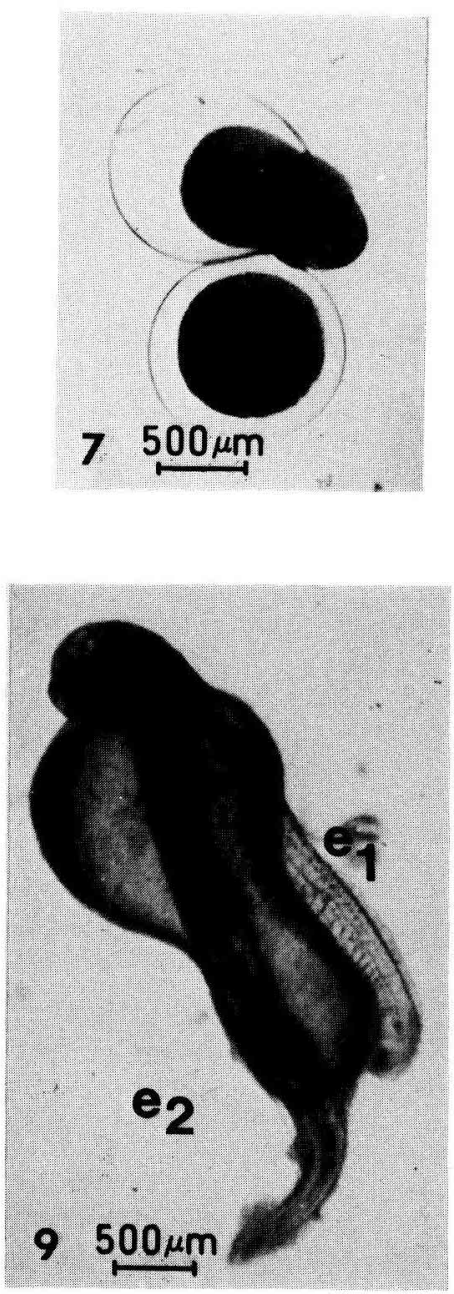
( $8 \mathrm{~min}$ ), des embryons âgés de $6 \mathrm{~h}$ meurent au cours de l'incubation, alors que leur coque avait apparemment résisté à la digestion enzymatique.

\section{Discussion.}

Digestion enzymatique de la coque. - Nos observations au microscope montrent que le moment crucial de la technique de préparation des embryons sans coque est celui où s'ouvre dans celle-ci un premier orifice : l'embryon subit alors ce que nous avons appelé une extrusion, qui est beaucoup plus brutale dans l'eau que dans une solution saline de même osmolarité que l'embryon (solution $\mathrm{H}$ ).

Pour expliquer cette différence, nous tenterons de présenter une interprétation des mécanismes qui président, au cours de l'activation, au gonflement de l'œuf. Dès sa mise à l'eau, le cytoplasme périphérique de l'ovocyte réagit par exocytose de vacuoles corticales dont le contenu mucoprotéique est retenu par la coque semi-perméable. Plus que par un processus osmotique, c'est donc, selon nous, par l'hydrophilie de polyélectrolytes corticaux qu'est provoqué l'appel d'eau décrit chez de nombreuses espèces de poissons (Devillers et al., 1953; Thomopoulos, 1953 ; Soin, 1977 ; Laale, 1980 ; Rubtsov, 1982 ; ...).

Il en résulte un gonflement de l'œuf qui distend la coque jusqu'à ce qu'un équilibre soit atteint avec la force de résistance élastique opposée par la coque, d'abord souple, puis progressivement durcie au cours de l'activation. L'œuf devient turgescent (Winnicki et Cykowska, 1973), et c'est la surpression hydrostatique dans l'espace périvitellin qui est responsable du phénomène d'extrusion que nous avons observé. Cependant, en solution saline, on sait que les polyélectroly. tes ont une affinité réduite pour l'eau (Rembaum et Selegny, 1975). D'autre part, nous avons observé, sur l'œuf de carpe (travail en cours), que l'exocytose des alvéoles corticaux y est retardée, ainsi que le gonflement de l'œuf ; cependant, celui-ci finit par être plus important que dans l'eau (Soin, 1977) et se traduit par la formation de sortes de hernies où la coque est amincie (fig. 8). II est donc proba-

FIG. 6. - Embryons vivants incubés jusqu'au stade 4-8 cellules après digestion de la coque par la trypsine avant le stade deux cel/ules. Incubation dans une solution saline isotonique : solution $H$ (cf. Matériel et méthodes).

FIG. 7. - "Extrusion" d'un embryon à travers le jer orifice formé dans la coque : extrusion douce dans la solution isotonique $H$ (cf. Matériel et méthodes) utilisée comme bain de lavage de la trypsine.

FIG. 8. - Embryon fécondé et incubé dans la solution saline $H$ légèrement diluée $(272 \mathrm{mosmol} / \mathrm{kg})$ : $\mathrm{d}$ : disque germinatif (stade morula âgée) ; epv : espace périvitellin hypertrophié : $\mathrm{h}$ : " hernie " en formation ; $m$ : tache micropylaire ; tv : travées cytoplasmiques intravitellines.

FIG. 9. - Embryon double vivant formé par accolement d'embryons sans coque avant épibolie et incubés jusqu'à un stade correspondant au stade de l'embryon éclos. $\mathrm{e}_{1}, \mathrm{e}_{2}$ : corps et queue des deux embryons accolés (les somites sont visibles).

FIG. 10. - Embryons vivants incubés jusqu'à un stade correspondant au stade de l'embryon éclos après digestion de la coque par la trypsine avant le stade deux cellules. 
ble que le durcissement de la coque est lui-même retardé, et sa résistance élastique diminuée. En solution saline, enfin, la pression hydrostatique de l'espace périvitellin de l'œuf de brochet est moins importante que dans l'eau (Loefler, 1971). Ainsi s'expliquerait que l'extrusion y soit moins traumatisante pour l'embryon.

D'ailleurs, la technique que nous avons élaborée, élimine la coque en deux temps : après une attaque rapide, la fin de la digestion s'effectue lentement dans le bain de lavage; la coque perd ainsi progressivement sa résistance élastique, tandis que les produits de la digestion des macromolécules périvitellines ont le temps de sortir à travers la coque perméabilisée ; la turgescence de l'œuf est alors réduite au moment où la coque se perce.

L'augmentation du rendement de la digestion de la coque immédiatement après la fécondation, pourrait s'expliquer par l'appel d'eau qui a lieu au début de l'activation ; la trypsine, entraînée avec l'eau dans l'espace périvitellin en formation, se trouve en contact avec la couche interne de la coque qui est plus facilement attaquable par les protéases que la couche externe (Smithberg, 1966). La digestion débute par la couche interne, ce qui se voit sous le microscope, et le gonflement qui a lieu à ce moment, amincit la coque, ce qui facilite l'attaque de la trypsine.

Après l'âge 10 min le rendement de la digestion enzymatique diminue pour s'annuler pratiquement à la fin de l'activation. Cette évolution, qui traduit les modifications physicochimiques liées au durcissement de la coque, a été constatée sur l'œuf de Notobranchius korkhause, lors de l'action de la pronase (Lesseps et Cast, 1976), ou sur l'œuf de carassin, entre le stade 1 cellule et le stade morula (Kobayasi, 1965). Si Smithberg (1966) n'observe pas de modification avec l'âge de la résistance de la coque d'Oryzias latipes à la pronase, c'est probablement qu'il commençait ses traitements après la fin de l'activation. Un traitement trop tardif pourrait aussi expliquer l'échec de certaines tentatives précédentes de digestion de la coque par la trypsine seule (Kanoh et Yamamoto, 1957 ; Smithberg, 1966).

Puisque l'activation correspond à l'acquisition d'une résistance élevée à l'action de la trypsine, et que les ovocytes surmatures sont eux-mêmes résistants à cette action, le vieillissement post-ovulatoire paraît correspondre à une sorte d'activation prématurée de l'œuf. D'ailleurs, l'étude de la cinétique comparée du gonflement en solution saline, d'ovocytes frais et surmatures, nous a conduit à une conclusion analogue (Sjafei, 1985).

Si les effets négatifs, sur le développement embryonnaire, de la surmaturation ovocytaire sont dus à un durcissement prématuré de la coque, ces effets devraient pouvoir être réduits par l'éliminationt de la coque. C'est ce que nous observons dans l'expérience 2 : les taux d'embryons vivants au 1 er jour d'incubation sont supérieurs à $50 \%$ après traitement par la trypsine, alors qu'ils ne sont que de $17,7 \%$ sur les lots témoins non traités.

Incubation des embryons sans coque. - Nous avons obtenu, dans nos essais d'incubation d'embryons sans coque, des mortalités survenues à des âges variés, et dont la cause nous a paru difficile à déterminer : étant donné la fragilité des embryons sans coque, un niveau excessif du système d'aération par bulles, 
des proliférations bactériennes ou fongiques (même en présence de nystatine et pénicilline-streptomycine), une poursuite de l'action de la trypsine malgré les lavages répétés, ont pu être mis en cause dans certaines expériences. De plus, il n'a pas toujours été possible de distinguer parmi les embryons survivants, ceux qui ont été débarrassés de leur coque avant la fin du lavage $\left(\mathrm{EC}^{-}\right)$, de ceux qui l'ont conservée $\left(\mathrm{EC}^{+}\right)$, et ont été décoqués plus tard, du fait de la poursuite de l'action de la trypsine pendant l'incubation. Cependant, dans des expériences comme l'expérience 4 (fig. $2 \mathrm{C}$ et 5), le pourcentage total des survivants est assez grand pour que l'on puisse comparer la capacité de divers milieux d'incubation à assurer le développement sans la coque, y compris pendant les stades embryonnaires les plus fragiles. Ainsi, dans l'expérience 4, en supposant même que tous les $\mathrm{EC}^{+}$ aient survécu jusqu'au $3^{\mathrm{e}}$ jour d'incubation, il reste que le taux de survie des $\mathrm{EC}^{-}$ est nettement plus élevé dans la solution $H$ que dans l'eau (fig. 5B). II ne s'agit pas là d'un effet dû à la sortie de la coque, puisque le bain de lavage de tous les lots est le même (solution $\mathrm{H}$ ). II semble donc que la solution $\mathrm{H}$ soit capable de jouer pour les embryons sans coque, le rôle joué normalement dans l'eau par la coque et le liquide périvitellin. Partant d'une étude de l'évolution des structures membranaires dans l'œuf du Brachydanio rerio (Roubaud et Pairault, 1980), nous avons émis I'hypothèse d'un rôle du liquide périvitellin dans l'association postmitotique des blastomères dont les liaisons sont affaiblies au moment de la division cellulaire. Comme le montre alors, l'association spontanée qui s'est produite par simple contact entre des embryons décoqués, l'un des rôles de la coque pourrait être d'empêcher non seulement la polyspermie, mais aussi, la formation d'embryons multiples.

Cependant, la surpression, qui s'exerce à l'intérieur de l'espace périvitelin, pourrait servir à compenser, pour les poissons d'eau douce, la tendance à l'éclatement par endosmose (Loefler et Lovtrup, 1970). S'il en est ainsi, il suffirait de fournir à l'embryon sans coque, un milieu isotonique pour assurer son développement normal. Effectivement, nous avons pu élever des $\mathrm{EC}^{-}$dans une solution de saccharose $0,3 \mathrm{M}$. Mais, du $1^{\text {er }}$ au $3^{\mathrm{e}}$ jour $\mathrm{d}^{\prime}$ incubation, les pourcentages de survie des embryons sans coque, en milieu isotonique, décroissent toujours fortement (fig. 5A et $\mathrm{C}$ ). II est donc possible que les besoins osmotiques de l'embryon évoluent au cours du temps, en particulier, en liaison avec la formation et l'étalement de la couche enveloppante.

En traitant les embryons, après action de la trypsine, par un inhibiteur de cet enzyme, en réalisant des conditions stériles d'incubation, et en adaptant l'osmolarité du milieu à l'évolution des besoins de l'embryon, nous pensons arriver à déterminer les conditions d'une technique de routine d'incubation en masse des embryons sans coque.

Reçu en avril 1985.

Accepté en décembre 1985.

Remerciements. - Pour leurs conseils et leur aide bibliographique : M. H. Magri et D. Marie, à Jouy-en-Josas, V. Korzh et A. A. Neyfakh à Moscou. Pour leur aide à la mise en œuvre et la discussion des expériences: T. Desira et D. S. Sjafei.

Ce travail a bénéficié des soutiens du Secrétariat à l'Environnement (contrat I.N.R.A. 8340170 ), du Ministère de I'Industrie et de la Recherche (contrat I.N.R.A. 8360 66) et du C.N.R.S. (RCP 0806 56). 


\section{References}

DEVILLERS C., THOMOPOULOS A., COLAS J., 1953. Differenciation bipolaire et formation de I'espace périvitellin dans l'œuf de Salmo irideus. Bull. Soc. Zool. Fr., 78, 462-470.

DESIRA T., 1984. Elaboration d'un test de toxicité utilisant la sensibilité de l'œuf de la carpe commune (Cyprinus carpio L) Mémoire DEA Toxicol. Univ. Paris 7.

GILLET C., ROUBAUD P., 1983. Influence sur la survie jusqu'à éclosion des embryons de carpe commune (Cyprinus carpio L.) après traitement pendant la fécondation et le développement précoce par le carbendazime, un fongicide de synthèse. Water Res., 17, 1343-1348.

HUVER C., 1963. A chemical technique for dechorionation teleost eggs. Copeia, 3, 591-592.

IWAMATSU T., 1983. A new technique for dechorionation and observation on the development of the naked egg in Oryzias latipes. The J. exp. Zool., 233, 83-89.

KANOH Y., YAMAMOTO T., 1957. Removal of the membrane of the dog salmon egg by means of proteolytic enzymes. Bull. jap. Soc. Sci. Fish., 23, 166-172.

KOBAYASI H., 1965. Removal of the membrane of the funa (Carassius carassius) egg. C. R. Hokkaido Univ., 16-22.

LAALE H., 1980. The perivitelline space and egg enveloppes of bony fish embryo. Anat. Rec., 187, 125-128.

LESSEPS R., CAST E., 1976. Proteolytic dechorionation of annual fish embryo. Anat. Rec., 187, $125-128$.

LOEFLER C. A., 1971. Water exchange in the pike egg. $J$. exp. Biol., 55, 797-811.

LOEFFLER C. A., LOVTRUP S., 1970. Water balance in the salmon egg. J. exp. Biol., 52, 291-298.

REMBAUM A., SELEGNY E., 1975. Polyelectrolytes and their applications D. Reidel Publs. Co, Doedrecht Holland.

ROUBAUD P., PAIRAULT C., 1980. Membrane differenciation in the pregastrula of the teleost Brachydanio rerio Hamilton Buchanan : a scanning electron microscope study. Reprod. Nutr. Dévelop., 20, 1515-1526.

RUBTSOV $V . \vee ., 1982$. The dependance of some morpho-physiological characteristics of the eggs of the carp (Cyprinus carpio L) on changes in the microstructure of the egg menbrane. $J$. Ichtyol., 32, 43-51.

SCHWARTZ D., 1963. Méthodes statistiques à l'usage des médecins et des biologistes. Ed. Med. Flammarion Paris.

SJAFEI D. S., 1985. Conservation et vieillissement in vitro des ovocytes ovulés de la carpe commune (Cyprinus carpio L.) Th. Doct. $3^{e}$ cycle. Univ. P. et M. Curie, Paris VI.

SMITHBERG M., 1966. An enzymatic procedure for dechorionating the fish embryo. Oryzias latipes. Anat. Rec., 154, 823-830.

SOIN S., 1977. Some features of the development of the carp (Cyprinus carpio) under hatchery conditions. J. lchthyol., 5, 759-769.

THOMOPOULOS A., 1953. Sur l'œuf de Perca fluviatilis. Bull. Soc. Zool. Fr. 78. 106-114.

WINNICKI A., CYKOWSKA C., 1973. New data on the mechanism of water uptake in salmon eggs. Acta ichthyol. piscatoria, 3, 3-9. 